\title{
Atividade fotossintética e peroxidação de lipídios de membrana em plantas de aroeira-do-sertão sob estresse hídrico e após reidratação
}

\author{
Cristina G. S. Queiroz*, Queila S. Garcia e José Pires Lemos Filho
}

Departamento de Botânica, Instituto de Ciências Biológicas, CP 486, Universidade Federal de Minas Gerais, 31270-901, Belo Horizonte, $M G$, Brasil; Corresponding author: queiroz@icb.ufmg.br

Avaliaram-se os efeitos do estresse hídrico e da reidratação sobre parâmetros de fluorescência, condutância estomática e peroxidação de lipídios em plantas de Myracrodruon urundeuva Fr. All. (Anacardiaceae). As plantas foram cultivadas em casa de vegetação e a seca foi induzida por suspensão da irrigação durante 14 dias. Sob estresse hídrico, observou-se queda acentuada no conteúdo relativo de água foliar, o qual alcançou valores próximos a 60 \%. Essa queda foi acompanhada por grande diminuição na condutância estomática e na taxa aparente de transporte de elétrons (ETR) e extensivos danos às membranas evidenciados por aumentos na peroxidação de lipídios. Apesar do decréscimo nos valores de ETR, não se observaram alterações nos valores do rendimento quântico potencial do fotossistema II (Fv/Fm) em conseqüência do estresse hídrico. Durante a fase de recuperação, as plantas apresentaram valores de condutância estomática, parâmetros de fluorescência e peroxidação lipídica similares àqueles verificados antes do período de seca. Todos os parâmetros fotossintéticos investigados mostraram valores normais $6 \mathrm{~h}$ após o início de reidratação. $\mathrm{O}$ ajuste linear entre os valores de condutância e ETR mostrou alta correlação entre essas duas variáveis, sugerindo que os estômatos representam o principal fator limitante da fotossíntese em plantas de Myracrodruon urundeuva sob estresse hídrico.

Palavras-chave: Condutância estomática, estresse oxidativo, fluorescência, fotossíntese, Myracrodruon urundeuva.

Photosynthetic activity and membrane lipid peroxidation of aroeira-do-sertão plants under water stress and after rehydration: The effects of water stress and rehydration on the fluorescence parameters, stomatal conductance, lipid peroxidation of Myracrodruon urundeuva Fr. All. (Anacardiaceae) plants were investigated. The plants were grown under greenhouse conditions and drought was induced by 14 days of witholding water. Under water stress the relative leaf water content decreased by up to $60 \%$. This decrease was associated with the decrease in stomatal conductance values and apparent photosynthetic electron transport rates (ETR) and extensive damage to membranes due to lipid peroxidation. Despite the decrease in ETR, no change in the potential quantum yield of Photosystem II (Fv/Fm) was observed as consequence of water stress. Following a recovering phase, the plants showed stomatal conductance, fluorescence parameters and lipid peroxidation values similar to those prior to drought induction. All photosynthetic parameters investigated showed normal values up to $6 \mathrm{~h}$ after the onset of rehydration. A linear relationship fitted to stomatal conductance and ETR showed that these two variables are highly correlated suggesting that stomata are the main limiting factor to photosynthesis in M. urundeuva plants under water stress.

Key words: Fluorescence, Myracrodruon urundeuva, oxidative stress, photosynthesis, stomatal conductance.

A aroeira-do-sertão, Myracrodruon urundeuva Fr. All. (Anacardiaceae), é uma espécie que, pela qualidade de sua madeira, de grande resistência mecânica, alta densidade e considerável durabilidade, é muito utilizada na construção civil, marcenaria e carpintaria (Lorenzi, 1992). É uma espécie de distribuição numa ampla faixa de variação climática, ocorrendo em matas subcaducifólias e caducifólias, freqüentemente em agrupamentos densos, em geral associados a afloramentos calcários (Flörsheim e Tomazello Filho, 1994). 
Tem sido reconhecido que as variações na disponibilidade de água podem afetar o estabelecimento e o crescimento inicial de espécies lenhosas, uma vez que o sistema radicular de plantas jovens é bastante superficial (Moreira e Klink, 2000) e, na estação seca, o potencial hídrico nas camadas superficiais do solo pode atingir valores inferiores ao do ponto de murcha permanente, descrito para espécies agrícolas (Franco et al., 1996). Além do efeito do estresse hídrico, sob condições naturais, a baixa disponibilidade de luz, em vista do sombreamento, conforme apontam Nardoto et al. (1998), também limita a produtividade de indivíduos jovens.

Sob condições de déficit hídrico, tem sido demonstrada a relação direta entre a redução da concentração intercelular de $\mathrm{CO}_{2}$, em razão do fechamento estomático, gerando decréscimos na assimilação do $\mathrm{CO}_{2} \mathrm{e}$ no rendimento quântico do fotossistema II (Baker, 1993). Entretanto, também tem sido relatado que sob estresse hídrico severo, além das restrições estomáticas no suprimento de $\mathrm{CO}_{2}$, podem ocorrer limitações em componentes não estomáticos, com danos nos centros de reação do fotossistema II, os quais podem apresentar reversão parcial após reidratação (Angelopoulos et al., 1996). Há evidências de que os efeitos do estresse hídrico sobre o fotossistema II podem ser mediados pela produção e acumulação de espécies reativas de oxigênio (Smirnoff, 1993; Lawlor, 1995), levando a extensivos danos às membranas, desencadeando processos peroxidativos de lipídios, com perda de eletrólitos pela célula (Alonso et al., 1997; Queiroz et al., 1998) e queda na atividade fotossintética (Smirnoff, 1993). Uma forma eficiente de monitorar danos fotooxidativos causados pelo estresse tem sido o uso de medidas da fluorescência da clorofila $a$ associada ao fotossistema II (PS II) (Baker, 1993; BolhàrNordenkampf e Öquist, 1993; Newton e McBeath, 1996).

Considerando as características dos sítios de ocorrência da aroeira, durante a regeneração natural, as plantas jovens estariam sujeitas tanto ao estresse hídrico como a limitações na disponibilidade de luz. Dessa forma, é presumível que, nos períodos de seca, ocorra grande restrição na transpiração, com decréscimos na atividade fotossintética sem, no entanto, haver danos acentuados no fotossistema II, pelas condições de sombreamento. O presente estudo investigou a resposta de mudas de aroeira ao estresse hídrico, sob níveis baixos de luz, em termos de limitações estomáticas e/ou na atividade do fotossistema
II, admitindo a ocorrência de uma rápida recuperação da atividade fotossintética após a suspensão do estresse.

Plantas de M. urundeuva, obtidas de sementes de uma população no município de Pedro Leopoldo - MG, foram cultivadas em sacos plásticos contendo uma mistura de solo argiloso com areia na proporção de 2:1 e mantidas em casa de vegetação por um ano, supridas com solução de Hoagland. Uma semana antes de iniciados os experimentos, transferiram-se as plantas para uma sala de crescimento, com fluxo quântico de $60 \mu \mathrm{mol} \cdot \mathrm{m}^{-2} \cdot \mathrm{s}^{-1}$ (ao nível das folhas), fotoperíodo de $12 \mathrm{~h}$ e temperatura de $27 \pm 2{ }^{\circ} \mathrm{C}$, onde foram mantidas durante a fase experimental (14 dias de suspensão da irrigação seguidos de 54 h de reidratação). O estresse hídrico foi imposto por suspensão da irrigação e a condutância estomática foi monitorada diariamente, utilizando-se porômetro de difusão AP4 (Delta T), até a verificação de valores de condutância correspondentes a cerca de $10 \%$ do valor registrado para plantas irrigadas. Todas as determinações foram realizadas em folhas maduras, de idade similar e mesma disposição no caule. Também avaliou-se nas folhas o conteúdo relativo de água (CRA), o grau de peroxidação de lipídios de membrana e o desempenho fotossintético. O nível de peroxidação de lipídios de membrana nos tecidos foliares foi medido em termos do conteúdo de malondialdeído (MDA, um produto de lipoperoxidação), determinado pela reação do ácido tiobarbitúrico (TBA), segundo método descrito por Dhindsa et al. (1981). O desempenho fotossintético foi avaliado por meio de medidas de fluorescência da clorofila $a$, sendo o rendimento quântico potencial do fotossistema II $(\mathrm{Fv} / \mathrm{Fm})$, determinado em folhas de plantas adaptadas ao escuro durante $1 \mathrm{~h}$, utilizando-se um medidor de fluorescência modulada (Mini-PAM, Walz) (Lemos-Filho, 2000). Determinou-se a performance fotossintética em função de níveis crescentes de luz durante 4 min, em oito estádios de $30 \mathrm{seg}$ cada um. Ao final de cada nível de luz, aplicou-se um pulso saturante $\left(6.000 \mu \mathrm{mol} . \mathrm{m}^{-2} . \mathrm{s}^{-1}\right)$ para a determinação de parâmetros de fluorescência. A taxa aparente de transporte de elétrons (ETR) foi determinada segundo Lüttge et al. (1998).

O delineamento experimental foi inteiramente casualizado, com quatro repetições, sendo os dados submetidos à análise da variância e, as médias, comparadas pelo teste de Tukey a $5 \%$ de probabilidade. Os dados das curvas de respostas à luz foram ajustados, utilizando-se equações polinomiais de segunda ordem. 
O nível de desidratação imposto às plantas de aroeira levou à diminuição da atividade fotossintética, caracterizada pela redução da condutância estomática, decréscimos na taxa máxima aparente de elétrons e desencadeamento de um processo lipoperoxidativo nas membranas (tabela 1). No entanto, até valores de CRA de cerca de $60 \%$ nas folhas não houve danos irreversíveis, com rápida recuperação da atividade fotossintética e do nível de peroxidação das membranas após a reidratação das plantas, sugerindo que, provavelmente, o sistema de defesa antioxidante foi ativado após o estresse hídrico. Sob condições normais, as plantas geralmente estão bem adaptadas para minimizar danos devidos à inevitável formação de espécies de oxigênio na fotossíntese (Foyer et al., 1994), porém a seca intensifica a formação de radicais livres em plantas por limitar o "pool" de $\mathrm{NADP}^{+}$disponível para aceitar elétrons do fotossistema I. Dessa maneira, aumenta a probabilidade de transferência de energia de excitação para $\mathrm{O}_{2}$, levando à produção de $\mathrm{O}_{2}^{-} \mathrm{e}^{1} \mathrm{O}_{2}$ e, conseqüentemente, peroxidação lipídica (Smirnoff, 1993). Após a retomada da irrigação, as plantas de aroeira mostraram acentuada redução na atividade peroxidativa foliar, possivelmente pela queda na geração de espécies livres de oxigênio e/ou ativação de um sistema antioxidante para captura desses radicais livres.

Embora tenha induzido decréscimos no CRA e aumentos na peroxidação lipídica, a suspensão da irrigação das plantas de aroeira não afetou a eficiência quântica potencial do fotossistema II - Fv/Fm (tabela 1). Isso pode ser atribuído às condições de baixa radiação $\left(60 \mu \mathrm{mol} \cdot \mathrm{m}^{-2} \cdot \mathrm{s}^{-1}\right)$ sob a qual as plantas permaneceram durante o período de estresse hídrico e de reidratação. Alguns trabalhos realiza- dos sob condições de radiação bem mais altas do que as mantidas durante este experimento mostram a ocorrência de fotoinibição, como relatado por Eickmeier et al. (1993), trabalhando com Selaginella lepidophylla, sob intensidades de luz de $2.000 \mu \mathrm{mol} . \mathrm{m}^{-2} . \mathrm{s}^{-1}$. No entanto, quando a dessecação ocorreu sob baixa intensidade luminosa, esses autores observaram que não ocorreu fotoinibição até valores de cerca de $40 \%$ de CRA. Nas plantas de S. lepidophylla submetidas à dessecação sob alta densidade de fluxo de fótons, nas quais foi observado decréscimo na relação $\mathrm{Fv} /$ Fm, as características da fluorescência da clorofila retornaram a valores próximos aos detectados na fase anterior à dessecação, após reidratação por 24 h sob baixa radiação. Em trabalho posterior, Casper et al. (1993) sugerem que sob condições de desidratação, mesmo níveis baixos de luz $\left(50 \mu \mathrm{mol} \cdot \mathrm{m}^{-2} \cdot \mathrm{s}^{-1}\right)$ podem tornar-se excessivos, em consequência da inibição da fixação de $\mathrm{CO}_{2}$, e a fotoproteção relacionada com o ciclo das zeaxantinas é desencadeada, minimizando os danos da fotoinibição. Além do fator intensidade de radiação, o nível do estresse hídrico é também um fator determinante na resposta das plantas. Em plantas de oliveira submetidas a diversos níveis de estresse hídrico, Angelopoulos et al. (1996) observaram decréscimos relativamente pequenos na capacidade de transporte de elétrons do fotossistema II sob condições de estresse moderado e uma diminuição significativa nas plantas sob estresse hídrico severo. Tais resultados indicam que o fossistema II foi o principal sítio afetado pelo estresse hídrico, e esses autores sugerem que a perda da sua função pode ser atribuída à diminuição no "turnover" da proteína D1 do centro de reação do fotossistema, conforme relatado por Hao et al. (1999).

Tabela 1. Conteúdo relativo de água (CRA), condutância estomática, rendimento quântico potencial do fotossistema II (Fv/Fm); taxa máxima aparente de transporte de elétrons (ETR) e nível de peroxidação de lipídios (teor de MDA) em folhas de plantas de Myracrodruon urundeuva Fr. All., irrigadas, sob estresse hídrico, e durante a reidratação.

\begin{tabular}{lccccc}
\hline Tratamento & $\begin{array}{c}\text { CRA } \\
(\%)\end{array}$ & $\begin{array}{c}\text { Condutância } \\
\left(\mathrm{mmol} \cdot \mathrm{m}^{-2} \cdot \mathrm{s}^{-1}\right)\end{array}$ & Fv/Fm & $\begin{array}{c}\text { ETR máxima } \\
\left(\mu \mathrm{mol} \cdot \mathrm{m}^{-2} \cdot \mathrm{s}^{-1}\right)^{(}\end{array}$ & $\begin{array}{c}\text { MDA } \\
\left(\mathrm{nmol} \cdot \mathrm{g}^{-1} \mathrm{MS}\right)\end{array}$ \\
\hline Irrigadas & $89,8 \pm 7,4^{\mathrm{a}}$ & $34,4 \pm 15,6$ & $0,804 \pm 0,004$ & $48,9 \pm 16,0$ & $266 \pm 24$ \\
Estresse hídrico & $61,8 \pm 10,5$ & $3,1 \pm 0,2$ & $0,798 \pm 0,009$ & $13,9 \pm 1,4$ & $350 \pm 34$ \\
6 h reidratação & $85,4 \pm 2,8$ & $23,6 \pm 11,9$ & $0,801 \pm 0,008$ & $33,6 \pm 7,6$ & $215 \pm 19$ \\
54 h reidratação & $89,2 \pm 3,0$ & $31,3 \pm 21,4$ & $0,813 \pm 0,005$ & $36,6 \pm 14,7$ & $230 \pm 28$ \\
\hline
\end{tabular}

a Os valores representam as médias e desvios padrão $( \pm)$ de 4 repetições. 
Os resultados obtidos neste trabalho mostram que o estresse hídrico aplicado às plantas de $M$. urundeuva não foi severo o suficiente para provocar fotoinibição, sugerindo que não houve danos no complexo coletor de luz do fotossistema II. No entanto, as curvas de ETR em função de níveis crescentes de radiação fotossinteticamente ativa (DFF) (figura 1A) demonstram que, nas plantas submetidas a estresse hídrico, a saturação de luz foi alcançada em níveis de radiação abaixo de $200 \mu \mathrm{mol} \cdot \mathrm{m}^{-2} \cdot \mathrm{s}^{-1}$, enquanto em plantas mantidas hidratadas, os valores de ETR máxima foram muito superiores aos obtidos sob estresse e a ETR máxima foi detectada em níveis de radiação mais elevados $\left(600 \mu \mathrm{mol} \cdot \mathrm{m}^{-2} \cdot \mathrm{s}^{-1}\right)$. Após a reidratação, verificou-se recuperação significativa da ETR máxima e da condutância estomática.

Os valores de ETR mostraram relação direta com a condutância estomática (figura 1B), à semelhança do que foi relatado por Lemos Filho (2000) para espécies do cerrado. Esses dados sugerem que o fechamento dos estômatos, ocorrido durante a suspensão da irrigação, tenha levado ao decréscimo na concentração intercelular de $\mathrm{CO}_{2}$ e na redução da assimilação desse gás e, por conseqüência, redução do fluxo de elétrons não cíclico. Há evidências de que grande proporção do fluxo de elétrons é desviada da assimilação de $\mathrm{CO}_{2}$ para a redução de $\mathrm{O}_{2}$, sob condições de estresse com baixa concentração intercelular de $\mathrm{CO}_{2}$, com aumentos na peroxidação lipídica, conforme detectado nas plantas de aroeira sob estresse hídrico. A partir de medidas de parâmetros de fluorescência e cálculo do rendimento quântico do fluxo de elétrons, Cornic e Briantais (1991) concluíram que a alocação de elétrons para o oxigênio aumenta, durante a dessecação foliar, como conseqüência de decréscimo na concentração intercelular de $\mathrm{CO}_{2}$. A limitação da absorção de $\mathrm{CO}_{2}$ pelo déficit hídrico pode, portanto, aumentar a formação de espécies de oxigênio reduzido e, conseqüentemente seu potencial para danos no aparato fotossintético (Lawlor, 1995).

Os dados obtidos neste trabalho permitem concluir que plantas jovens de aroeira, sob estresse hídrico em níveis baixos de luz, tem a atividade fotossintética reduzida mais em função da limitação na condutância estomática do que a danos irreversíveis ao fotossistema II, ainda que tenham sido detectados níveis elevados de peroxidação lipídica, revertidos logo após a reidratação.
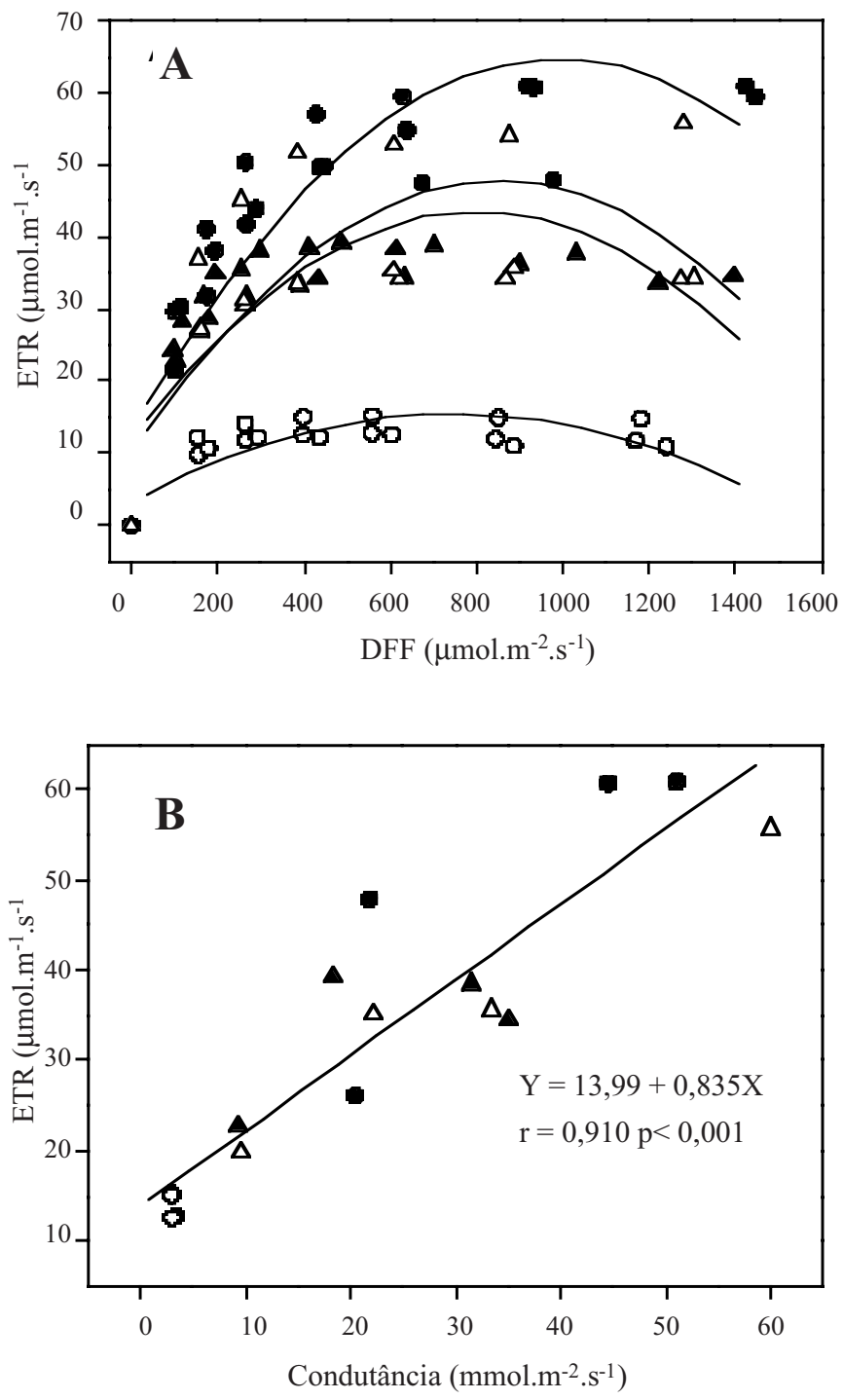

Figura 1. Efeito do estresse hídrico sobre a atividade fotossintética de M. urundeuva.. (A) Taxa relativa de transporte de elétrons (ETR) em função de níveis crescentes de radiação fotossinteticamente ativa (DFF), e (B) correlação entre taxa relativa de transporte de elétrons (ETR) e condutância estomática em plantas irrigadas $(\bullet)$, sob estresse hídrico (o) e após 6 horas $(\mathbf{\Delta})$ e 54 horas de reidratação $(\Delta)$. Para a figura A: $(\bullet)$ $\mathrm{Y}=12,9915+0,1046 \mathrm{X}-0,000052 \mathrm{X}^{2}, \mathrm{R}^{2}=0,8072$, $\mathrm{P}<0,0001$; (o) $\mathrm{Y}=3,21+0,032 \mathrm{X}-0,000022 \mathrm{X}^{2}$, $\mathrm{R}^{2}=0,7030, \mathrm{P}<0,0001$; (ム) $\mathrm{Y}=11,8696+0,079 \mathrm{X}$ $0,000049 \mathrm{X}^{2}, \mathrm{R}^{2}=0,6945, \mathrm{P}<0,0001 ; \quad(\Delta) \mathrm{Y}=9,7233+$ $0,08972 X-0,000053 X^{2}, R^{2}=0,6102, P<0,0002$. 


\section{REFERÊNCIAS}

Alonso A, Queiroz CS, Magalhães AC (1997) Chilling stress leads to increased cell membrane rigidity in roots of coffee (Coffea arabica L.) seedlings. Biochim. Biophys. Acta 1323:75-84.

Angelopoulos K, Dichio B, Xiloyannis C (1996) Inhibition of photosynthesis in olive trees (Olea europaea L.) during water stress and rewatering. J. Exp. Bot. 47:1093-1100.

Baker NR (1993) Light-use efficiency and photoinhibition of photosynthesis in plants under environmental stress. In: Smith JAC, Griffiths H (eds.), Water deficits plant responses from cell to community, pp.221-235. Bios Scientific Publisher, Oxford.

Bolhàr-Nordenkampf HR, Öquist G (1993) Chlorophyll fluorescence as a tool in photosynthesis research. In: Hall D, Scurlock JMO, Bolhàr-Nordenkampf HRR, Leegood CRC, Long SP (eds), Photosynthesis and production in a changing environment, pp.193206. Chapman \& Hall, London.

Casper C, Eickmeier WG, Osmond CB (1993) Changes of fluorescence and xanthopyll pigments during dehydration in the resurrection plant Selaginella lepidophylla in low and medium light intensities. Oecologia 94:528-533.

Cornic G, Briantais J-M (1991) Partitioning of photosynthetic electron flow between $\mathrm{CO}_{2}$ and $\mathrm{O}_{2}$ reduction in a $\mathrm{C}_{3}$ leaf (Phaseolus vulgaris $\mathrm{L}$.) at different $\mathrm{CO}_{2}$ concentrations and during drought stress. Planta 183:178-184.

Dhindsa RS, Plumb-Dhindsa P, Thorpe TA (1981) Leaf senescence: correlated with increased levels of membrane permeability and lipid peroxidation, and decreased levels of superoxide dismutase and catalase. J. Exp. Bot. 32:93-101.

Eickmeier WG, Casper C, Osmond CB (1993) Chlorophyll fluorescence in the resurrection plant Selaginella lepidophylla (Hook. \& Grev.) spring during high-light and desiccation stress, and evidence for zeaxanthinassociated photoprotection. Planta 189:30-38.

Flörsheim SMB, Tomazello Filho M (1994) Dendrologia e Anatomia da madeira de aroeira Myracrodruon urundeuva F. F. \& M. F. Allemão (Anacardiaceae). Rev. Inst. Flor. 6:75-85.
Foyer CH, Lelandais M, Kunert KJ (1994) Photooxidative stress in plants. Physiol. Plant. 92:696-717.

Franco AC, Nardoto GB, Souza MP (1996) Patterns of soil water potential and seedlings survival in the cerrados of central Brazil. In: Anais do VIII Simpósio sobre o cerrado, Brasília, pp.277-280. EMBRAPA/CPAC, Brasília.

Hao L, Liang H, Wang Z, Liu X (1999) Effects of water stress and rewatering on turnover and gene expression of photosystem II reaction center polypeptide D1 in Zea mays. Aust. J. Plant. Physiol. 26:375-378.

Lawlor DW (1995) The effects of water deficit on photosynthesis. In: Smirnoff N (ed), Environmental and plant metabolism-flexibility and acclimation, pp.129-160. Bios Scientific Publisher, Oxford.

Lemos-Filho JP (2000) Fotoinibição em três espécies de cerrado (Annona crassifolia, Eugenia dysenterica e Campomanesia adamantium) na estação seca e na chuvosa. Rev. Bras. Bot. 23:45 -50.

Lorenzi H (1992) Árvores brasileiras. Manual de cultivo e identificação de plantas arbóreas nativas do Brasil. Editora Plantarum, Nova Odessa.

Lüttge U, Haridasan M, Fernandes GW, Mattos EA, Trimborn P, Franco AC, Caldas LS, Ziegler H (1998) Photosynthesis of mistletoes in relation to their hosts at various sites in tropical Brazil. Trees 12:167-174.

Moreira AG, Klink CA (2000) Biomass allocation and growth of tree seedlings from two contrasting Brazilian savannas. Ecotropicos 13:43-51.

Nardoto GB, Souza MP, Franco AC (1998) Estabelecimento e padrões sazonais de produtividade de Kielmeyera coriacea (Spr) Mart. nos cerrados do Planalto Central: efeitos do estress hídrico e sombreamento. Rev. Bras. Bot. 21:313-319.

Newton AC, McBeath C (1996) The impact of desiccation on chlorophyll fluorescence in detached leaves of six tropical tree species. Photosynthetica 32:491-501.

Queiroz CGS, Alonso A, Mares-Guia ML, Magalhães AC (1998) Chilling-induced changes in membrane fluidity and antioxidant enzyme activities in roots of (Coffea arabica L.) seedlings. Biol. Plant. 41:403-413.

Smirnoff N (1993) The role of active oxygen in the response of plants to water deficit and dessiccation. New Phytol. 125:27-58. 